\title{
Germinação, crescimento e desenvolvimento in vitro de orquídeas (Cattleya spp., Orchidaceae)
}

\author{
Danieli Schneiders ${ }^{1}$, Rosete Pescador ${ }^{2 *}$, Maristela Raitz Booz ${ }^{3}$, Rogério Mamoru Suzuki ${ }^{4}$
}

\section{RESUMO}

As orquídeas no ambiente natural sofrem exploração devido a sua importância ornamental, levando algumas espécies à extinção. O cultivo in vitro é uma forma alternativa para a conservação $e x$-situ. Procurou-se determinar um meio de cultura eficiente para a germinação in vitro de sementes e o crescimento inicial de plântulas de Cattleya forbesii, bem como para o crescimento de plântulas in vitro de Cattleya harrisoniana. No primeiro caso, sementes foram inoculadas em meio de cultura básico de Murashige \& Skoog (MS) = T1 e MS básico acrescido de 2,5 g L-1 de carvão ativado $(\mathrm{CA})=\mathrm{T} 2$. No segundo, plântulas com $1 \pm 0,2 \mathrm{~cm}$ de altura foram submetidas aos tratamentos T1, T2, MS com a metade da concentração original de macro-micronutrientes (T3) e MS com a metade da concentração original de macro-micronutrientes suplementado com 1,25 $\mathrm{g} \mathrm{L}^{-1}$ de CA (T4). Verificou-se aos 30 dias em C. forbesii uma porcentagem de germinação de $45 \%$ em T1 e $90 \%$ em T2. A adição de CA ao meio de cultura trouxe aumento na altura de plântulas de $C$. forbesii de acordo com análises realizadas aos 180 dias de cultivo. Em relação ao crescimento de $C$. harrisoniana, aos 240 dias observou-se que todos os parâmetros médios avaliados (altura da parte aérea, massa de matéria fresca total, número de raízes e folhas, comprimento da maior raiz e diâmetro do pseudocaule) foram significativamente maiores em T2. Dessa forma, sugere-se o uso do meio MS acrescido de 2,5 $\mathrm{g} \mathrm{L}^{-1}$ de CA (T2), uma vez que é significativamente favorável tanto para a germinação de sementes quanto para o crescimento de ambas as espécies.

Palavras-chave: carvão ativado, meio de cultura, micropropagação, orquídeas.

\section{ABSTRACT}

\section{Germination, growth and development in vitro of orchids of the genus Cattleya}

Orchids are over-exploited in their natural environment due to their ornamental importance, which is leading some species to extinction. In vitro culture is an alternative for ex-situ conservation. Our objective was to determine an efficient medium for in vitro seed germination and initial seedling growth of Cattleya forbesii and Cattleya harrisoniana. Seeds of Cattleya forbesii were incubated in Murashige \& Skoog (MS) medium (T1) and MS added with 2,5 g L $\mathrm{L}^{-1}$ of activated charcoal (T2). For the last, plants with $1 \pm 0,2 \mathrm{~cm}$ of height were submitted to the following treatments: T1, T2, MS reduced to the half strenght (T3) and MS reduced to the half strenght supplemented with $1,25 \mathrm{~g} \mathrm{~L}^{-1}$ of activated charcoal (T4). Thirty days after seed inoculation of $C$. forbesii, it was verified $45 \%$ and $90 \%$ of germination in $\mathrm{T} 1$ and $\mathrm{T} 2$, respectively. The addition of activated charcoal also promoted an increase in the height of the $C$. forbesii seedlings

Recebido para publicação em 10/12/2009 e aprovado em 24/02/2012

'Bióloga. Mestranda em Engenharia Ambiental, Programa de Pós-Graduação em Engenharia Ambiental, Universidade Regional de Blumenau, Rua Antônio da Veiga, 140, Victor Konder, 89012-900, Blumenau, Santa Catarina, Brasil. s.danieli@yahoo.com.br

${ }^{2}$ Engenheira-Agrônoma, Doutora. Departamento de Fitotecnia, Pós-Graduação em Recursos Genéticos Vegetais, Universidade Federal de Santa Catarina, Rodovia Admar Gonzaga, Km 3, Itacorubi, 88034-001, Florianópolis, Santa Catarina, Brasil e-mail: rosete@cca.ufsc.br (*autora para correspondência).

${ }^{3}$ Bacharel em Biologia e Ciências Contábeis, Mestre. Programa de Pós-Graduação em Engenharia Ambiental, Universidade Regional de Blumenau, Rua Antônio da Veiga, 140, Victor Konder, 89012-900, Blumenau, Santa Catarina, Brasil. maristela.rb@terra.com.br

${ }^{4}$ Biólogo, Doutor. Pesquisador Científico, Núcleo de Pesquisa Orquidário do Estado, Instituto de Botânica, Av. Miguel Stefano, 3687, Água Funda, 04301-902, São Paulo, São Paulo, Brasil.rogeriomsuzuki@yahoo.com.br 
after 180 days of in vitro cultivation. After 240 days of culture of $C$. harrisoniana shoot height, total fresh mass, number of roots and leaves, length of the largest root and diameter of the shoots were significantly stimulated in $\mathrm{T} 2$ compared to the other treatments. We suggest the use of MS medium added with 2,5 $\mathrm{g} \mathrm{L}^{-1}$ of activated charcoal because is significantly favorable for seed germination and initial growth for both species.

Key words: activated charcoal, medium culture, micropropagation, orchids.

\section{INTRODUÇÃO}

As orquídeas são plantas herbáceas perenes bastante diversificadas quanto ao tamanho, à forma dos caules e folhas e à cor das flores. Espécies de orquídeas são comercialmente cultivadas para produção e venda em vaso e de flores para arranjos ornamentais (Tombolato \& Costa, 1998).

Devido às características ornamentais, as orquídeas apresentam relevante importância econômica, por isso são retiradas excessivamente da natureza, levando inúmeras espécies à extinção. Nas duas últimas décadas, as técnicas de cultivo in vitro têm sido utilizadas para a propagação de orquídeas, para o estudo de aspectos fisiológicos relacionados ao crescimento e desenvolvimento e como método de conservação $e x$-situ para redução do risco de extinção (Ferreira \& Suzuki, 2008).

Cattleya L. é um gênero de orquídea intensamente comercializado na atualidade. Agrupa inúmeras espécies e milhares de híbridos que apresentam flores grandes e vivamente coloridas (Paula \& Silva, 2004). A maioria das pesquisas em propagação vegetal de orquídeas está pautada na produção de protocolos de germinação ou organogênese in vitro, como multiplicação de Cattleya $\mathrm{x}$ mesquitae L. C. Menezes (Ramos \& Carneiro, 2007), desenvolvimento de plantas de Cattleya loddigesii Lindl., após a germinação (Moraes et al., 2009), e propagação de Cattleya walkeriana Gardner e Schomburgkia crispa Lindl. (Sousa et al., 2007).

Cattleya forbesii Lindl. e Cattleya harrisoniana Bateman ex Lindl. var. alba Barb.Rodr. são importantes espécies por causa da beleza de suas flores. C. forbesii é de médio porte, com cerca de $20 \mathrm{~cm}$ de altura e duas a quatro flores, em geral de coloração marrom a amarela, de labelo rosa a amarelo-ouro e sépalas e pétalas finas (Cardoso \& Israel, 2005). A variedade alba de C. harrisoniana é caracterizada por apresentar fácil florescimento, geralmente no final do verão, e altura de uma planta adulta de até $20 \mathrm{~cm}$, com duas a três flores de coloração violeta e labelo de pontas amarelas, pseudobulbo delgado e folhas estreitas (Withner, 1988).

A germinação de sementes de orquídeas in vitro vem sendo realizada desde o início do século passado, quan- do Knudson (1922) descreveu a germinação em meio de cultura asséptico. De acordo com Martini et al. (2001), a semeadura assimbiótica de orquídeas constitui técnica bastante relevante do ponto de vista comercial e ecológico. As plantas produzidas dessa forma podem ser utilizadas em programas de reintrodução de espécies nativas em áreas de preservação ambiental devido à variabilidade genética gerada pelo explante. O sucesso na tecnologia e aplicação dos métodos de cultura in vitro deve-se à melhor compreensão dos requerimentos nutricionais das células e dos tecidos em cultura. A formulação do meio de cultura é essencial para o explante, pois possibilita a presença dos constituintes necessários (minerais, vitaminas, reguladores de crescimento etc.) para seu desenvolvimento, podendo ser formulado com diferentes combinações, de acordo com os requerimentos de cada espécie (Faria et al., 2002).

Dentre os produtos que podem ser adicionados aos meios de cultura está o carvão ativado, que tem promovido alguns efeitos benéficos como melhores condições no desenvolvimento de embriões (Chagas et al., 2005) e maior crescimento de raízes (Ribeiro et al., 2000). Isso se atribui à presença de uma excelente rede de poros com grande superfície interna na estrutura do carvão ativado, em que muitas substâncias inibitórias do meio ou produtos tóxicos liberados pelos explantes podem permanecer adsorvidos (Chagas et al., 2005; Thomas, 2008).

Diante do exposto, o objetivo deste trabalho foi determinar um meio de cultura eficiente para germinação das sementes e crescimento inicial in vitro das plântulas de C. forbesii e para o crescimento de plântulas de $C$. harrisoniana.

\section{MATERIAL E MÉTODOS}

\section{Espécies utilizadas e obtenção do material vegetal}

A cápsula com as sementes de $C$. forbesii e as plântulas da variedade alba de $C$. harrisoniana foram obtidas a partir de indivíduos selecionados da coleção viva do Laboratório de Biotecnologia e Micropropagação Vegetal da Universidade Regional de Blumenau - FURB, Santa Catarina, Brasil. 


\section{Germinação das sementes e crescimento in vitro de Cattleya forbesii}

Foram coletadas duas cápsulas fechadas contendo sementes maduras de $C$. forbesii. As sementes foram submetidas à assepsia por meio de solução de hipoclorito de sódio $1,5 \%$ durante 10 minutos, e em seguida foram realizadas três lavagens consecutivas com água destilada e esterilizada a $120^{\circ} \mathrm{C}$ sob 1,2 atm, durante 40 minutos em autoclave.

O meio de cultura Murashige \& Skoog (1962) (MS) desprovido de carvão ativado (T1) e contendo $2,5 \mathrm{~g} \mathrm{~L}^{-1} \mathrm{de}$ carvão ativado (T2) foi utilizado para a germinação das sementes. Ambos os tratamentos foram suplementados com $0,4 \mathrm{mg} \mathrm{L}^{-1}$ de tiamina, $100 \mathrm{mg} \mathrm{L}^{-1}$ de inositol, $2 \%$ de sacarose e $0,7 \%$ de ágar. $\mathrm{O}$ pH dos meios foi ajustado para $5,8 \pm 0,05$ antes da adição do ágar e, em seguida, foi esterilizado a $120^{\circ} \mathrm{C}$ e $1 \mathrm{~atm}$, durante 20 minutos.

Posteriormente, em câmara de fluxo laminar horizontal, pequenas porções de sementes foram retiradas das cápsulas e colocadas em frascos com $60 \mathrm{~mL}$ de meio de cultura. Os frascos contendo as sementes foram mantidos em sala de cultura com fotoperíodo de 16 horas, sob $25 \pm 2{ }^{\circ} \mathrm{C}$ e densidade de fluxo de fótons de $50 \mu \mathrm{mol} \mathrm{m}^{-2} \mathrm{~s}^{-1}$.

O delineamento experimental utilizado foi o inteiramente casualizado, com dois tratamentos e cinco repetições, cada uma representada por um frasco. Trinta dias após a inoculação das sementes, foi realizada a análise da porcentagem de germinação a partir da retirada de cinco amostras de cada tratamento; ou seja, de cinco frascos dos diferentes tratamentos. Foram consideradas sementes germinadas aquelas que apresentavam protocormos de coloração verde. Aos 180 dias de cultivo, o crescimento inicial foi analisado por meio da altura média das plântulas através de escala em centímetro presente na parede externa do frasco.

\section{Crescimento in vitro de Cattleya harrisoniana}

Para a realização deste experimento foram selecionadas 10 plântulas de $C$. harrisoniana var. alba com $1 \pm 0,2 \mathrm{~cm}$ de altura, obtidas da germinação in vitro de sementes em meio MS, as quais foram transferidas para frascos contendo $60 \mathrm{~mL}$ de meio de cultura.

Os tratamentos adotados foram: meio MS (T1); meio MS suplementado com 2,5 $\mathrm{g} \mathrm{L}^{-1}$ de carvão ativado (T2); meio MS com a metade da concentração original de macromicronutrientes (T3); e meio MS com a metade da concentração original de macro-micronutrientes suplementado com 1,25 $\mathrm{g} \mathrm{L}^{-1}$ de carvão ativado (T4).

Independentemente do tratamento utilizado, os meios de cultura foram acrescidos de tiamina, inositol, sacarose e ágar nas mesmas concentrações descritas para a germinação de $C$. forbesii. As plântulas, depois de inoculadas, permaneceram nas mesmas condições laboratoriais que as do ensaio anterior.

Dessa forma, o delineamento experimental foi o inteiramente casualizado, com quatro tratamentos, sete repetições e 10 plântulas por repetição. Duzentos e quarenta dias após o início do experimento foram avaliadas as seguintes variáveis médias: altura da parte aérea (considerando a base do pseudocaule até a extremidade da folha maior), massa de matéria fresca total, número de raízes e folhas, comprimento da maior raiz e diâmetro do pseudocaule. Diferenças significativas entre os tratamentos (média das sete repetições) foram avaliadas por análise de variância (ANOVA) e complementados pelo teste de Tukey-Kramer a 5\% de significância. A distribuição normal dos dados foi verificada pelo teste de Shapiro-Wilk no software PAST versão 2.13 (Hammer et al., 2001).

\section{RESULTADOS E DISCUSSÃO}

\section{Germinação das sementes e crescimento inicial in vitro de Cattleya forbesii}

Adotou-se a fase de protocormo como a efetiva germinação de sementes dessa espécie, pois nas descrições de Arditti (1992) e Kraus et al. (2006) o padrão de germinação de sementes de orquídeas é bastante uniforme; ou seja, as sementes começam a intumescer, o que leva ao rompimento do tegumento seminal e à liberação do embrião. Este se desenvolve numa estrutura tuberiforme geralmente clorofilada, como foi verificado neste estudo, chamada de protocormo.

As sementes de $C$. forbesii germinaram aos 30 dias após a semeadura, independentemente do tratamento (T1 e T2) (Tabela 1), tendo o meio MS contendo carvão ativado (T2) promovido maior taxa de germinação das sementes em comparação com o T1, $90 \pm 3 \%$ e $45 \pm 3 \%$, respectivamente.

No que se refere ao tempo de germinação, Santos et al. (2007), utilizando sementes de Cattleya bicolor Lindl., observaram a formação dos protocormos aos 20 dias após a inoculação das sementes em quaisquer dos tratamentos utilizados, independentemente da adição de diferentes concentrações de ácido naftalenoacético e ácido giberélico. Pereira et al. (2005) obtiveram 90\% de germinação de Oncidium flexuosum Sims sete dias após a

Tabela 1. Taxa de germinação de sementes de Cattleya forbesii obtida trinta dias após a semeadura in vitro

\begin{tabular}{|c|c|}
\hline Meios de cultura & Germinabilidade (\%) \\
\hline $\mathrm{T} 1$ & $45 \pm 3$ \\
\hline $\mathrm{T} 2$ & $90 \pm 3$ \\
\hline
\end{tabular}
acrescido de $2,5 \mathrm{~g} \mathrm{~L}^{-1}$ de carvão ativado. 
inoculação simbiótica das sementes, período significativamente menor ao observado neste estudo, que foi de 30 dias. As análises realizadas aos 180 dias revelaram que os protocormos se desenvolveram em plântulas com média de 1,2 cm de altura em T2 e 0,4 cm em T1 (Figura 1). Nota-se que o tratamento T2 influenciou positivamente a germinação de sementes, bem como o crescimento inicial das plântulas devido à adição de $2,5 \mathrm{~g} \mathrm{~L}^{-1}$ de carvão ativado.

Confirmando os resultados supracitados, Znaniecka et al. (2005) constataram que os meios de cultura Fast (1981) e PB $_{2}$ (Kukulczanka \& Paluch, 1971), suplementados com carvão ativado, foram muito eficientes para a germinação de sementes e para o crescimento das mudas de Encyclia aff. oncidioides Schltr. Hossain (2008) constatou no meio M (Mitra et al., 1976) que Epidendrum ibaguense Kunth. na presença de carvão ativado aumentou o número de sementes germinadas, estimulou o enraizamento precoce das plântulas e induziu significativamente a formação de protocormos de maior tamanho $(1,63 \pm 18 \mathrm{~mm})$ em comparação com meios desprovidos desse componente $(1,16 \pm 18 \mathrm{~mm})$.

A adição de carvão ativado no meio de cultura é uma prática reconhecida, e sua influência na diferença de altura média das plântulas pode ser atribuída à adsorção de substâncias inibitórias do meio ou à adsorção de produtos tóxicos liberados pelos explantes, pela manutenção do $\mathrm{pH}$ em valor ótimo para morfogênese (Pasqual et al., 2001; Thomas, 2008) e liberação de substâncias naturalmente presentes no carvão que poderiam promover o crescimento e escurecimento dos meios de cultura. Por outro lado, de acordo com Thomas (2008), o carvão ativado poderia atuar na adsorção de vitaminas, íons metálicos e reguladores de crescimento, resultando em efeitos positivos ou negativos para o desenvolvimento, dependendo da espécie.

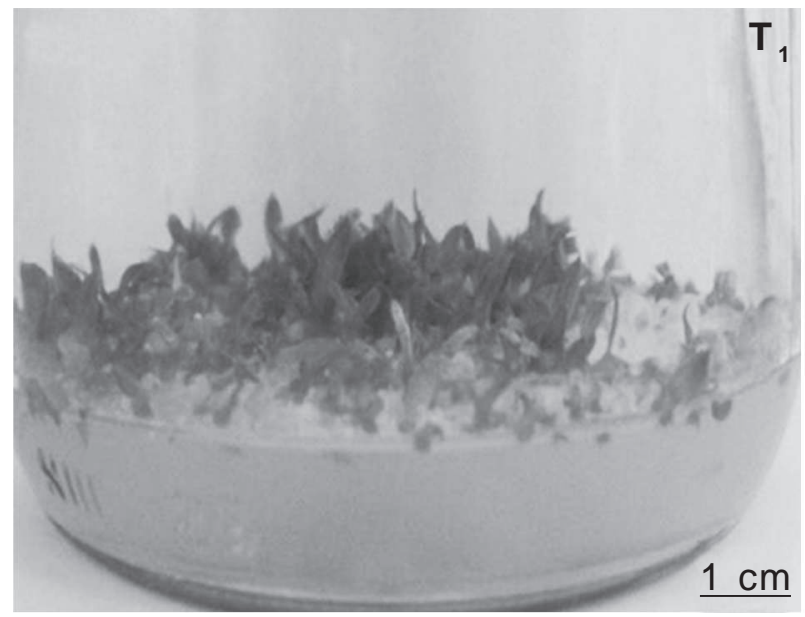

Como observado neste estudo, o carvão ativado é eficiente na promoção do desenvolvimento in vitro de plantas de diferentes famílias: Bromeliaceae, Vriesea gigantea Gaudich. e Vriesea philippocoburgii Wawra (Droste et al., 2005); Piperaceae, Piper nigrum Linn. (Moura et al., 2008); e Ericaceae, Vaccinium ashei Reade e Vaccinium corymbosum L. (Mirtilo) (Damiani \& Schuch, 2009).

\section{Crescimento in vitro de Cattleya harrisoniana}

Após 240 dias de cultivo in vitro, verificou-se que nas culturas de $C$. harrisoniana a adição de carvão ativado ao meio MS (T2) promoveu significativamente o desenvolvimento das plântulas em relação àquelas cultivadas nos demais tratamentos, apresentando valores maiores para todas as variáveis avaliadas (Tabela 2). Embora não diferisse significativamente dos tratamentos T1 e T3, as plântulas desenvolvidas no meio MS com a metade da concentração original de macro-micronutrientes e com 1,25 $\mathrm{g} \mathrm{L}^{-1}$ de carvão ativado (T4) apresentaram maiores valores biométricos, sendo T4 o segundo melhor meio de cultura para o desenvolvimento de $C$. harrisoniana (Tabela 2).

A altura da parte aérea das plântulas inoculadas no tratamento T2 (MS com 2,5 $\mathrm{g} \mathrm{L}^{-1}$ de carvão ativado) $(6,62$ $\mathrm{cm}$ ) foi 54,6\% maior que no tratamento T4 (MS com a metade da concentração original de macro-micronutrientes e com 1,25 $\mathrm{g} \mathrm{L}^{-1}$ de carvão ativado) $(4,28 \mathrm{~cm})$. A massa de matéria fresca total $(0,37 \mathrm{~g})$ das plântulas crescidas no tratamento T2 foi $85 \%$ maior do que no tratamento T4 $(0,20 \mathrm{~g})$ (Tabela 2, Figura 2). De forma semelhante, Mohamed-Yasseen (2001) verificou aumento do comprimento de plântulas de milho quando da presença de carvão ativado no meio de cultura. Com a adição de $2,0 \mathrm{~g} \mathrm{~L}^{-1}$ de carvão ativado no meio de cultura composto de $3 / 4$ da concentração original do meio MS, Quoirin et al. (2001) observaram aumento na altura de plântulas de Acacia mearnsii De Wild., uma espécie de leguminosa. Por outro lado, Unemoto et al. (2006), avalian-

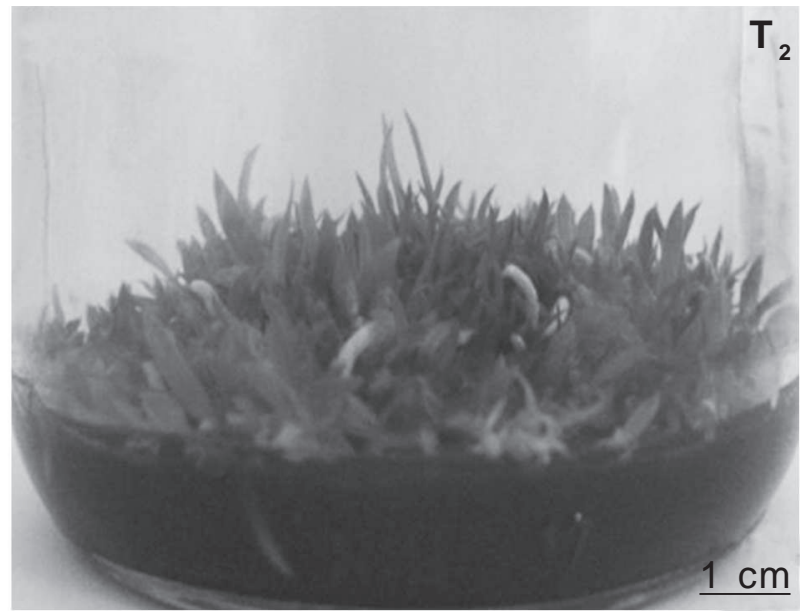

Figura 1. Plântulas de Cattleya forbesii após 180 dias de incubação em T1 (meio MS), com 0,4 cm de altura média, e em T2 (meio MS acrescido de 2,5 $\mathrm{g} \mathrm{L}^{-1}$ de carvão ativado), com altura média de $1,2 \mathrm{~cm}$.

Rev. Ceres, Viçosa, v. 59, n.2, p. 185-191, mar/abr, 2012 
do os efeitos de diferentes diluições do meio MS e da adição de carvão ativado a esses meios para a micropropagação de Sinningia leucotricha H. E. Moore (Gesneriaceae), verificaram que nos meios contendo carvão ativado o desenvolvimento da parte aérea e a massa de matéria fresca total foram inibidos. Dessa forma, a adição de carvão ativado nem sempre apresenta resultado positivo para o crescimento vegetal, e as condições de cultivo são específicas para cada espécie.

Em relação ao número médio de raízes e ao comprimento médio da raiz maior, os valores médios obtidos foram 6,09 e 3,89 cm, respectivamente, para as plântulas do tratamento T2, o qual foi estatisticamente superior aos demais meios de cultura (Tabela 2, Figura 2). Segundo George (1993), o escurecimento do meio de cultura pro- movido pelo carvão ativado simulando uma condição de escuro promoveria o melhor desenvolvimento do sistema radicular. Entretanto, Erig et al. (2004) verificaram que o enraizamento in vitro em pereira (Pyrus communis L., Rosaceae) não foi influenciado pela presença de carvão ativado no meio de cultura, demonstrando mais uma vez que a adição de carvão ativado no meio de cultivo pode não ser benéfica.

O número médio de folhas $(5,21)$ e o diâmetro médio do pseudocaule $(2,28 \mathrm{~mm})$ apresentado pelas plântulas do tratamento T2 foram, respectivamente, $5 \%$ e $54 \%$ superiores aos encontrados em plântulas do tratamento T4, e $24,9 \%$ e $100 \%$ maiores que os menores parâmetros verificados, respectivamente nas plântulas dos tratamentos T1 e T3 (Tabela 2, Figura 2).

Tabela 2. Efeitos de diferentes meios de cultura na altura média da parte aérea, média da massa de matéria fresca total, número médio de raízes e folhas, comprimento médio da raiz maior e diâmetro médio do caule nos diferentes tratamentos após 240 dias de cultivo in vitro de Cattleya harrisoniana

\begin{tabular}{lcccc}
\hline Parâmetros analisados & T1 & T2 & T3 & T4 \\
\hline Altura da parte aérea $(\mathrm{cm})$ & $3,37 \mathrm{~b}$ & $6,62 \mathrm{a}$ & $3,37 \mathrm{~b}$ & $4,28 \mathrm{~b}$ \\
Massa de matéria fresca total $(\mathrm{g})$ & $0,10 \mathrm{~b}$ & $0,37 \mathrm{a}$ & $0,13 \mathrm{~b}$ & $0,20 \mathrm{~b}$ \\
$\mathrm{~N}^{\circ}$ de raízes & $3,70 \mathrm{~b}$ & $6,09 \mathrm{a}$ & $3,93 \mathrm{~b}$ & $4,54 \mathrm{~b}$ \\
Comp. da maior raiz $(\mathrm{cm})$ & $1,95 \mathrm{~b}$ & $3,89 \mathrm{a}$ & $2,03 \mathrm{~b}$ & $2,47 \mathrm{~b}$ \\
$\mathrm{~N}^{\circ}$ de folhas & $4,17 \mathrm{~b}$ & $5,21 \mathrm{a}$ & $4,24 \mathrm{~b}$ & $4,94 \mathrm{~b}$ \\
Diâmetro do pseudocaule $(\mathrm{mm})$ & $1,35 \mathrm{~b}$ & $2,28 \mathrm{a}$ & $1,14 \mathrm{~b}$ & $1,48 \mathrm{~b}$ \\
\hline
\end{tabular}

$\mathrm{T} 1$ = meio MS, T2 = meio MS acrescido de 2,5 $\mathrm{g} \mathrm{L}^{-1}$ de carvão ativado, T3 = meio MS com a metade da concentração original de macromicronutrientes, T4 = meio MS com a metade da concentração original de macro-micronutrientes e acrescido de $1,25 \mathrm{~g} \mathrm{~L}^{-1}$ de carvão ativado. Letras diferentes indicam variação significativa entre os valores médios dos tratamentos para cada parâmetro nas linhas, segundo teste de Tukey $(\mathrm{P}<0,05)$.
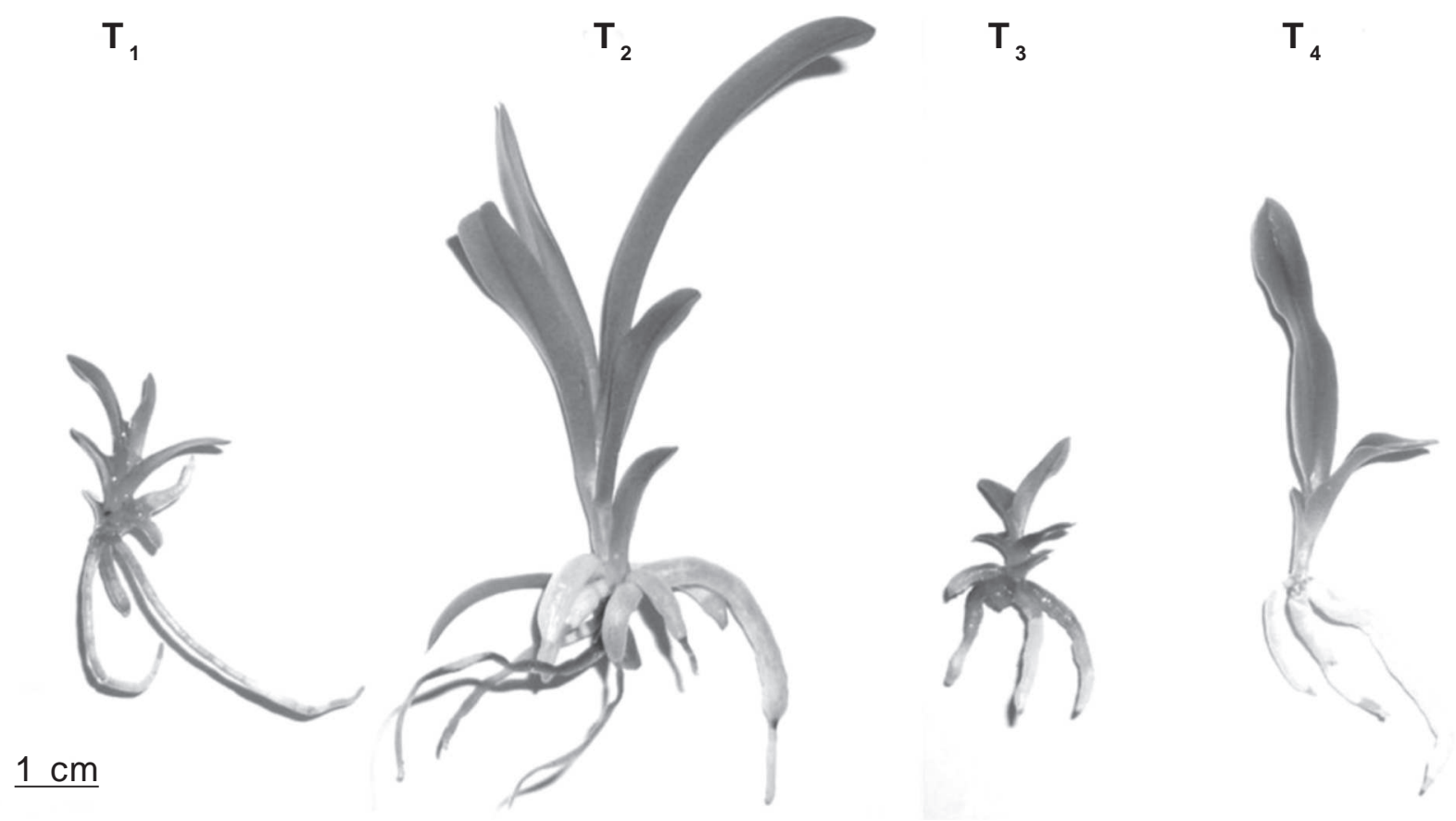

Figura 2. Plântulas de Cattleya harrisoniana após 240 dias de desenvolvimento em diferentes meios de cultura. T1 = meio MS, T2 = meio MS acrescido de 2,5 g L ${ }^{-1}$ de carvão ativado, T3 = meio MS com a metade da concentração original de macro-micronutrientes, $\mathrm{T} 4$ = meio MS com a metade da concentração original de macro-micronutrientes e acrescido de $1,25 \mathrm{~g} \mathrm{~L}^{-1}$ de carvão ativado. 
Diferentes respostas foram observadas no meio de cultura e da concentração de carvão ativado empregada, dependendo da espécie utilizada. Lee \& Lee (2003) obtiveram resultados positivos na regeneração de brotos e raízes a partir de protocormoides de Cypripedium formosanum Hayata adicionando $1 \mathrm{~g} \mathrm{~L}^{-1}$ de carvão ativado ao meio MS com $1 / 4$ da concentração de sais. Ket et al. (2004) observaram que a adição de $1 \mathrm{~g} \mathrm{~L}^{-1}$ ao meio Hyponex suplementado de $0,1 \mathrm{~g} \mathrm{~L}^{-1}$ de benziladenina e 1-2 $\mathrm{mg} \mathrm{L}^{-1}$ de thidiazuron promovia a formação múltipla de brotos em segmentos nodais de Anoectochilus formosanus Hayata, entretanto o crescimento era lento e os caules não se alongavam. O último comportamento foi revertido retirando-se os reguladores de crescimento e reduzindo para $0,5 \mathrm{~g} \mathrm{~L}^{-1}$ a concentração de carvão ativado adicionado. Shiau et al. (2005) mostraram que o desenvolvimento das plântulas de Haemaria discolor Lindl. era favorecido no meio MS reduzido em metade da sua concentração de nutrientes e com a adição de $2 \mathrm{~g} \mathrm{~L}^{-1}$ de carvão ativado.

Contrariamente, Pedroza-Manrique \& Mican-Gutierrez (2006) verificaram que o carvão ativado adicionado a três diferentes meios de cultura, incluindo o MS, não favoreceu a germinação de sementes ou o desenvolvimento das plântulas de Odontoglossum gloriosum Linden \& Rchb.f. Uma resposta diferente foi obtida por Pierik et al. (1988) em Paphiopedilum ciliolare Pfitzer, pois o carvão ativado não favorecia a germinação de sementes; entretanto, a adição $2 \mathrm{~g} \mathrm{~L}^{-1}$ estimulava o desenvolvimento das plântulas nas fases posteriores à germinação. Os resultados mais positivos neste trabalho foram obtidos quando se utilizou a composição completa do meio de cultura de MS acrescido de carvão ativado (Tabela 2).

A utilização do meio MS mostrou resultados bastante contrastantes para outras espécies de orquídeas. Stewart \& Kane (2006), estudando a germinação e o desenvolvimento inicial de Habenaria macroceratitis Willd., verificaram que não houve sequer a formação do protomeristema quando utilizaram esse meio de cultura, ocasionando a morte dos protocormos. Sorace et al. (2008) avaliaram o crescimento in vitro de Oncidium baueri Lindl. em diferentes concentrações de macronutrientes e sacarose. Esses autores constataram que o desenvolvimento vegetativo e o enraizamento da orquídea foram mais eficientes no tratamento contendo $40 \mathrm{~g} \mathrm{~L}^{-1} \mathrm{de}$ sacarose e a metade da concentração dos macronutrientes do meio MS.

Dutra et al. (2009) observaram que em Cyrtopodium punctatum (L.) Lindl. as plântulas desenvolveram-se mais rapidamente, apresentando a promoção do alongamento de caules no meio de MS com metade da concentração de nutrientes. Suzuki et al. (2009) verificaram que o meio MS não promoveu o crescimento de plântulas de Hadrolaelia tenebrosa (Rolfe) Chiron \& V.P. Castro. Suzuki et al. (2010) constataram em Cattleya bicolor Lindl. que o meio MS foi o que promoveu aumento significativo do número de folhas, das massas de matéria fresca e seca de caules e da massa de matéria seca de raízes. Esses resultados contrastantes reforçam a teoria de que há um meio de cultura específico para cada espécie de orquídea, não podendo generalizar um meio de cultura nem mesmo para espécies próximas filogeneticamente.

\section{CONCLUSÃO}

Diante do exposto, percebe-se que Cattleya forbesii e C. harrisonina desenvolvem-se mais rapidamente em meio básico de Murashige \& Skoog (MS), ou seja, com força total de macro e micronutrientes e $2,5 \mathrm{~g} \mathrm{~L}^{-1}$ de carvão ativado.

\section{AGRADECIMENTOS}

Ao Dr. Eduardo Pereira Cabral Gomes, do Núcleo de Pesquisa em Ecologia - Instituto de Botânica, pelo auxílio na Análise Estatística e na realização do teste de ShapiroWilk. À fonte financiadora: Universidade Regional de Blumenau - FURB, Programa PIPe/Artigo 170 e Fundação Fritz Muller-FFM.

\section{REFERÊNCIAS}

Arditti J (1992) Fundamentals of orchid biology. New York, John Wiley \& Sons. 530p.

Cardoso JC \& Israel M (2005) Levantamento de espécies da família Orchidaceae em Águas de Santa Bárbara (SP) e seu cultivo. Horticultura Brasileira, 23:169-173.

Chagas EA, Pasqual M, Ramos JD, Pio LAS, Dutra LF \& Cazetta JO (2005) Cultivo de embriões imaturos de citros em diferentes concentrações de carvão ativado e ácido giberélico. Ciência e Agrotecnologia, 29:1125-1131.

Damiani CR \& Schuch MW (2009) Diferentes substratos e ambientes no enraizamento in vitro de mirtilo. Ciência Rural, 39:563566.

Droste A, Silva AM, Matos AV \& Almeida WA (2005) In vitro culture of Vriesea gigantea and Vriesea philippocoburgii: two vulnerable bromeliads native to Southern Brazil. Brazilian Archives of Biology and Technology, 48:717-722.

Dutra D, Kane ME \& Richardson L (2009) Asymbiotic seed germination and in vitro seedling development of Cyrtopodium punctatum: a propagation protocol for an endangered Florida native orchid. Plant Cell Tissue Organ Culture, 96:235-243.

Erig AC, Schuch MW \& Braga EJB (2004) Enraizamento in vitro de pereira (Pyrus communis L.) cv. Carrick. Ciência Rural, 34:275-277.

Faria RT, Santiago DC, Saridakis D P, Albino UB \& Araújo R (2002) Preservation of the brazilian orchid Cattleya walkeriana Gardner using in vitro propagation. Crop Breeding and Applied Biotechnology, 2:489-492.

Fast G (1981) Orchideen Kultur. Stuttgart, Verlag Eugen Ulmer. 220 p. 
Ferreira WM \& Suzuki RM (2008) O cultivo in vitro de orquídeas como alternativa para a preservação de espécies nativas ameaçadas de extinção. In: Loiola MIB, Baseia IG \& Lichston JE (Org.) Atualidades, desafios e perspectiva da botânica no Brasil. Natal, Imagem Gráfica, p.67-68.

George EF (1993) Plant propagation by tissue culture. Part 1. The technology. England, Exegetics Ltd. Edington Wilts. 574p.

Hammer $\varnothing$, Harper DAT \& Ryan PD (2001) PAST: Paleontological Statistics Software Package for Education and Data Analysis. Palaeontologia Electronica 4(1): 9p. (http://palaeoelectronica.org/2001_1/past/issue1_01.htm).

Hossain MM (2008) Asymbiotic seed germination and in vitro seedling development of Epidendrum ibaguense Kunth. (Orchidaceae). African Journal of Biotechnology, 7:3614-3619.

Ket NV, Hahn EJ, Park SY, Chakrabarty D \& Paek KY (2004) Micropropagation of an endangered orchid Anoectochilus formosanus. Biologia Plantarum, 48:338-344.

Knudson L (1922) Non-symbiotic germination of orchid seed. Botanical Gazette, 73:1-25.

Kraus JE, Kerbauy GB \& Monteiro WR (2006) Desenvolvimento de protocormos de Catasetum pileatum Rchb. F. in vitro: aspectos estruturais e conceituais. Hoehnea, 33:177-184.

Kukulczanka K \& Paluch B (1971) Zastosowanie peptonu Peptobak-Bacutil w hodowli merystematycznej tkanki Cymbidium Sw. Acta Agrobotanica XXIV, 1:52-62.

Lee YI \& Lee N (2003) Plant regeneration from protocormderived callus of Cypripedium formosanum. In Vitro Cellular \& Developmental Biology. Plant, 39:475-479.

Martini PC, Willadino L, Alves GD \& Donato VMTS (2001) Propagação de orquídea Gongora quinquenervis por semeadura in vitro. Pesquisa Agropecuária Brasileira, 36:1319-1324.

Mitra GC, Prasad RN \& Roychowdary A (1976) Inorganic salts and differentiation of protocorms in seed-callus of an orchid and correlated changes in its free amino acid content. Indian Journal of Experimental Biology. 14:350-351.

Mohamed-Yasseen Y (2001) Influence of agar and activated charcoal on uptake of gibberellins and plant morphogenesis in vitro. Cellular and Developmental Biology Plant, 37:204-205.

Moraes CP, Diogo JA, Pedro NP, Canabrava RI, Martini GA \& Marteline MA (2009) Desenvolvimento in vitro de Cattleya loddigesii Lindley (Orchidaceae) utilizando fertilizantes comerciais. Revista Brasileira de Biociências, 7:67-69.

Moura EF, Menezes IC \& De Lemos OF (2008) Concentrações de citocinina e carvão ativado na micropropagação de pimentado-reino. Ciência Rural, 38:72-76.

Murashige TE \& Skoog F (1962) A revised medium for rapid growth and bioassays with tobacco tissue cultures. Physiologiae Plantarum, 15:473-497.

Pasqual M, Ramos JD \& Dutra LF (2001) Aplicações no melhoramento genético de plantas. Dissertação de Mestrado. Universidade Federal de Lavras, Lavras. 79p.

Paula CC \& Silva HMP (2004) Cultivo prático de orquídeas. $3^{a}$ ed. Viçosa, UFV. 106p.

Pedroza-Manrique J \& Mican-Gutierrez Y (2006) Asymbiotic germination of Odontoglossum gloriosum Rchb. F. (Orchidaceae) under in vitro conditions. In Vitro Cellular \& Developmental Biology. Plant, 42:543-547.

Pereira OL, Kasuya MCM, Rollemberg CL \& Borges AC (2005) Indução in vitro da germinação de sementes de Oncidium flexuosum (Orchidaceae) por fungos micorrízicos rizoctonióides. Revista Brasileira de Ciência do Solo, 29:199-206.
Pierik, RLM, Sprenkels PA, van der Harst B \& van der Meys QG (1988) Seed germination and further development of plantlets of Paphiopedilum ciliolare Pfitz. in vitro. Scientia Horticulturae, 34:139-153.

Quoirin M, Silva MC, Martins KG \& De Oliveira DE (2001) Multiplication of juvenile black wattle by microcuttings. Plant Cell, Tissue and Organ Culture, 66:199-205.

Ramos TV \& Carneiro IF (2007) Multiplicação in vitro de Cattleya $\mathrm{x}$ mesquitae pelo método de estiolamento de segmentos caulinares. Pesquisa Agropecuária Brasileira, 37:10-15.

Ribeiro VG, Sanábio D, Souza CN, Lopes PSN, Bocardo MR \& Pasqual M (2000) Efeito de ácido giberélico e carvão ativado no cultivo in vitro de Citrus limonia Osbeck X Poncirus trifoliata (L.) RAF. Pesquisa Agropecuaria Brasileira, 35:27-30.

Santos GA, Saito BC, Monteiro DP, Gutierre MAM \& Zonetti PC (2007) Utilização de reguladores hormonais na germinação e formação de plântulas in vitro de orquídeas. Cesumar, 9:07-12.

Shiau YJ, Nalawade SM, Hsai CN \& Tsay HS (2005) Propagation of Haemaria discolor via in vitro seed germination. Biologia Plantarum, 49:341-346.

Sorace M, Faria RT, Damasceno Junior CV, Gomes GP, Barbosa CM, Vieira FGN, Silva GL, Takahashi LSA \& Schnitzer JA (2008) Crescimento in vitro de Oncidium baueri (Orchidaceae) em diferentes concentrações de macronutrientes e sacarose. Ciências Agrárias, 29:775-782.

Sousa GC, Campos MRC \& Clemente PL (2007) Contaminação microbiana na propagação in vitro de Cattleya walkeriana e Schomburgkia crispa. Revista Brasileira de Biociências, 5:405407.

Stewart SL \& Kane ME (2006) Asymbiotic seed germination and in vitro seedling development of Habenaria macroceratitis (Orchidaceae) a rare Florida terrestrial orchid. Plant Cell Tissue and Organ Culture, 86:147-158.

Suzuki RM, Moreira VC, Nakabashi M \& Ferreira WM (2009) Estudo da germinação e crescimento in vitro de Hadrolaelia tenebrosa (Rolfe) Chiron \& V.P. Castro (Orchidaceae), uma espécie da flora brasileira ameaçada de extinção. Hoehnea, 36:657-666.

Suzuki RM, Almeida V, Pescador R \& Ferreira WM (2010) Germinação e crescimento in vitro de Cattleya bicolor Lindley (Orchidaceae). Hoehnea, 37:731-742.

Thomas TD (2008) The role of activated charcoal in plant tissue culture. Biotechnology Advances, 26:618-631.

Tombolato AFC \& Costa AMM (1998) Micropropagação de plantas ornamentais. Campinas, Instituto Agronômico. 72p. (Boletim técnico 174)

Unemoto LK, Faria RT, Meneguce B \& Assis AM (2006) Estabelecimento de um protocolo para a propagação in vitro de rainha-do-abismo, Sinningia leucotricha (Hoehne) Moore(Gesneriaceae). Acta Scientiarum. Agronomy, 28:503-506.

Withner CL (1988) The Cattleyas and their relatives, I. The Cattleyas. Portland, Timber Press. 147p.

Znaniecka J, Królicka A, Sidwa-Gorycka M, Rybczynski JJ, Szlachetko DL \& Lojkowska E (2005) Asymbiotic germination, seedling development and plantlet propagation of Encyclia aff. oncidioides - an endangered orchid. Acta Societatis Botanicorum Poloniae, 74:193-198.

Rev. Ceres, Viçosa, v. 59, n.2, p. 185-191, mar/abr, 2012 